\title{
CHANGE PATTERN EXPLORATION WITH HIERARCHICAL BI-CLUSTERING ON SENTINEL-1 SAR AND NIGHTTIME LIGHT DATA
}

\author{
Meiqin Che ${ }^{1}$, Paolo Gamba ${ }^{1}$ \\ ${ }^{1}$ Department of Electrical, Computer and Biomedical Engineering, University of Pavia, Italy \\ - meiqin.che01@universitadipavia.it,paolo.gamba@unipv.it
}

KEY WORDS: Sentinel-1, SAR, Nighttime night,Change pattern, Exploration, Hierarchical bi-clustering

\begin{abstract}
:
In the last few decades, urbanization activities have promoted the emergence of megacities, megalopolis, urban clusters or large urban aggregations, but only a few studies have analyzed them using remote sensing data in both the spatial and the temporal domains. In this paper, combining SAR and multispectral sensors with different resolutions, a novel approach, improved by means of a hierarchical clustering technique, is proposed. Urban changes are mapped in the form of multiple spatio-temporal patterns, visualized by change vectors exploiting the combination of SAR and nighttime light data.
\end{abstract}

\section{INTRODUCTION}

In the last ten years, the harmonization of rapid urbanization and increased economic activity in and around urban areas, along with the accompanying environmental pollution and land use change, has been the most important concern for the urban development policy in many different countries, e.g., in P.R. China (Wang et al., 2014, Wu et al., 2016). Accordingly, an urgent and challenging task is to improve the knowledge and understanding of change patterns in human settlements, especially for fast-urbanized urban aggregations in Africa, South America, as well as South and East Asia. Indeed, although in the last years a lot of studies have focused on human settlements and urban land use using multispectral and radar data (Lo, Choi, 2004, Gamba, Herold, 2009, Corbane et al., 2017), only recently more attention has been attracted to explore the changes in spatial patterns and volumetric distributions of artificial structures occurring inside urban areas by using heterogeneous sensors(Borghys et al., 2007). Indeed, some fusion techniques have been employed in urban mapping and urbanization monitoring using heterogeneous data sets of different resolutions and modalities (Taubenböck et al., 2012, Salentinig, Gamba, 2016, Tuong et al., 2018, Padmanaban et al., 2019). However, very few approaches, especially in an unsupervised way, have focused on mapping multitemporal patterns due to complex urbanization phenomena. Specifically, it has been proved that it is now possible to decouple changes due to urban expansion from those due to an increasing economic activity (Frolking et al., 2013, Huang et al., 2016).

Along this research line, and following our previous work (Che, Gamba, 2019), in this paper multi-temporal Sentinel1 Synthetic Aperture C-band data and Visible Infrared Imaging Radiometer Suite (VIIRS) nighttime measurements (also called the Day/Night Band, or DNB) are combined to explore urban change patterns at the geographical scale of the so-called "megacities" or "megalopolis". The joint use of heterogeneous sensors allows an unsupervised discover of spatio-temporal features and deeper relationships between urban constructions and nighttime-light changes, which in turn reveal the connections between built-up area changes and economic development. To this aim, a hierarchical bi-clustering algorithm is used to address the uncertainty in the number of patterns extracted from the data, with the final goal to automatically explore meaningful change patterns in urbanization activities.

\section{METHODOLOGY}

The procedure used in this work relies on the processing chain described in a previous work by the same authors (Che, Gamba, 2019). First of all, Sentinel-1 SAR is used to extract urban extents. This step ensures that the focus of the analysis is in built-up areas at the finest spatial resolution for freely available data sets. To handle big-size data over each megalopolis, a cluster of geographically adjacent metropolitan areas that may be somehow separated or merged into a continuous urban region, the critical preprocessing steps and computations are performed in Google Earth Engine (GEE) (Rutkowski et al., 2018). Then, a data-driven unsupervised classification is used to explore change patterns according to a feature space joining the base and the change images. In this way, both the initial state and the temporal change pattern are considered. Specifically, the initial and difference data by SAR and nighttime light sensors, including the $\mathrm{VV} \sigma_{0}, \mathrm{VV} \sigma_{0}, \mathrm{NL} \tau$ at the starting date of the considered time period and the change of backscattering coefficient VV $\Delta \sigma_{0}$, VH $\Delta \sigma_{0}$, change of Nighttime Light $\Delta \tau$, are considered. They are combined and analyzed according to the procedure described in the next section.

The peculiar step introduced in this work is a more effective unsupervised clustering as opposed to the paper (Che, Gamba, 2019), and includes the joint exploitation of three different algorithms: K-means, GMM (Gaussian mixed model with EM algorithm) (Pernkopf, Bouchaffra, 2005), VBGM (Variational Bayesian Gaussian Mixture) (Blei et al., 2017). These techniques are adaptively applied to the same feature space. Following this step, the procedure in (Che, Gamba, 2019) is resumed, and a 2-dimensional change vector analysis is applied to interpret the clustering results. Considering the resolution difference between the Nighttime light sensor and Sentinel-1 SAR, downscaling is applied to the SAR images to match VIIRS images at 500-meter resolution. However, in this paper, due to the wide geographical area to analyze, and the fact that it contains several metropolitan regions that are spatially disconnected, this vector analysis is performed at the object level, i.e., after that each 
agglomerate of urban pixels is extracted by connected component analysis. While more details about most of these steps are available in (Che, Gamba, 2019), the heterogeneous clustering procedure is the novel part proposed in this paper, and will be described in detail in the following subsection.

\subsection{Hierarchical clustering}

The performance of unsupervised classifiers depends on the data geometrical distribution in the feature space, as well as on the exploited clustering principle. Accordingly, clustering applied to (very) heterogeneous data from different sources poses challenging issues with respect to the recognition of reliable clusters. Specifically, it may happen that a few observations often acquire ambiguous class or cluster labels when multiple classifiers are applied to the same feature space. This is especially true for outliers or noisy measurements. In turn, this issue may mask interesting patterns of urban changes for our research. In this paper, a hierarchical 2-component clustering approach is applied to more reliably extract change patterns in urban built-up areas. The clustering begins from what we call the "root clustering", obtained by applying binary clustering by means of multiple algorithms (the above-mentioned k-means, GMM, VGMM), retaining only "reliable" clustering results and excluding "ambiguous" ones. By the term "reliable" here we consider (see Fig. 2) results that are consistently labeled as belonging to the same cluster, identified by its mean representative point. Next step is a further refinement of the binary clustering restricted to the reliable clustering results, once again looking for stability in the assignment to clusters by multiple classifiers. The procedure, schematically represented in Fig. 1, eventually ends after a few iterations (three, in this paper), providing reliable and unreliable clusters of data points. Further analysis is therefore focused on reliable clusters only, reducing possible issues and misinterpretations.

\section{EXPERIMENTAL RESULTS}

Following (Wang, Zheng, 2006), a "megalopolis" is a cluster of multiple urban areas where usually the government policy aims at knitting the area together more tightly and promoting development through transportation and communication links. In this paper, we focus on two megalopolis in China, namely the Jingjinji Metropolitan Region (Taofang, 2005) and the Yangtze River Delta (Yu, Wu, 2005), which correspond to the currently most developed and the most densely populated portions in P.R.China. These cities have boomed in population and economy for decades and are in the path to become the largest megalopolis in the world.

After two iterations of the hierarchical bi-clustering approach, the procedure generates four clusters, and the scatterplots for every possible feature pair of the feature space for the Jingjinji megalopolis are shown in Fig.3. In the second layer of the hierarchical clustering system, new clusters are obtained by separating the "parent clusters" and more detailed change patterns are revealed. The red and green clusters obtained from the parent cluster in the upper layer represent a further subdivision of the core area into its more stable part and the transition areas towards the fast developing urban fringe, and are consistent with the well-known urban circle structure of Beijing, and its pattern of urban outward expansion.

Within a relative short time-interval (in this work we are considering the interval from 2015 to 2018), the urban expansion is limited. More obvious changes occur in villages and towns surrounding the main built-up area, and this is visible in areas belonging to the yellow and blue clusters in Figs.3(a) and 3(b). The 4-component clusters allow recognizing more urban expansion patterns. Indeed, the blue and yellow clusters are discriminated thanks to different change directions for the backscattering coefficient (i.e., the change in built-up structures). As shown in Fig.3, the new constructions recognized as elements of the blue cluster commonly and frequently occur beyond the suburban area, and often accompany demolitions (recognized as elements of the yellow cluster).

Looking in more detail to the urban change patterns extracted by this technique, it is possible to appreciate that they are different depending on the urban size. For instance, among the three considered Chinese megalopolises, the expansion of cities with population over 8 million people, like Beijing, Tianjin, Shanghai and Nanjing, is spatially discontinuous and starts from towns away from main built-up area. Cities like Xingtai and Wuhu, which are smaller, spread randomly in all directions and more continuously in space. Patterns are even more complex and rich of information when considering 8 components clustering. The above-mentioned core urban areas (the red cluster in the 4 component map) are further separated into purple and red clusters. Both clusters correspond to almost no changes for the Jingjinji and Yangtze River Delta megalopolis, because of the highly developed infrastructure supporting a variety of entertainment and commercial activities. The suburban areas (subdivided into green and olive clusters), corresponds to areas with lower building density and more low-rise buildings, with lighting facilities utilized to support the public transportation rather than entertainment and commercial activities.

As for the external and fast changing areas, the 8 components clusters help to single out different changes in terms of feature magnitude and direction (increase or decrease). For instance, the blue cluster in Fig.5 shows a $10-20 \%$ increase in VV $\sigma_{0}$ but no change in $\mathrm{NL} \tau$ and $\mathrm{VH} \sigma_{0}$, which means no change in volume scattering and no spatial overflow and saturation of light, and this can be explained with construction activities for low density and low-rise building away from the core urban area. A more detailed interpretation is reported in table 1 and 2 for Yangtze River Delta and Jingjinji megalopolis, respectively.

Comparing the spatial location of these changes (Fig. 4), it becomes apparent that most construction activities has occurred far away from core urban areas, in the airport area, close to factories, ports and villa districts. Urban extents and clusters recognized as significant changes have been verified as presented in table 3 according to built-up layer in OpenStreetMap and Google historical images.

\section{CONCLUSIONS}

In this work, an object-oriented vector analysis applied to the clusters extracted via a novel hierarchical bi-clustering algorithm applied to SAR and nighttime light data results in clusters that can be interpret by looking at their temporal and spatial patterns. The approach was tested in fast-developing cities in China. The results shows the effectiveness of proposed method in mapping multi-pattern changes using remote sensing data from heterogeneous sources, even without determining the number of clusters beforehand.

The implemented hierarchical bi-clustering procedure provides more reliable clusters and highlights interesting urban change 


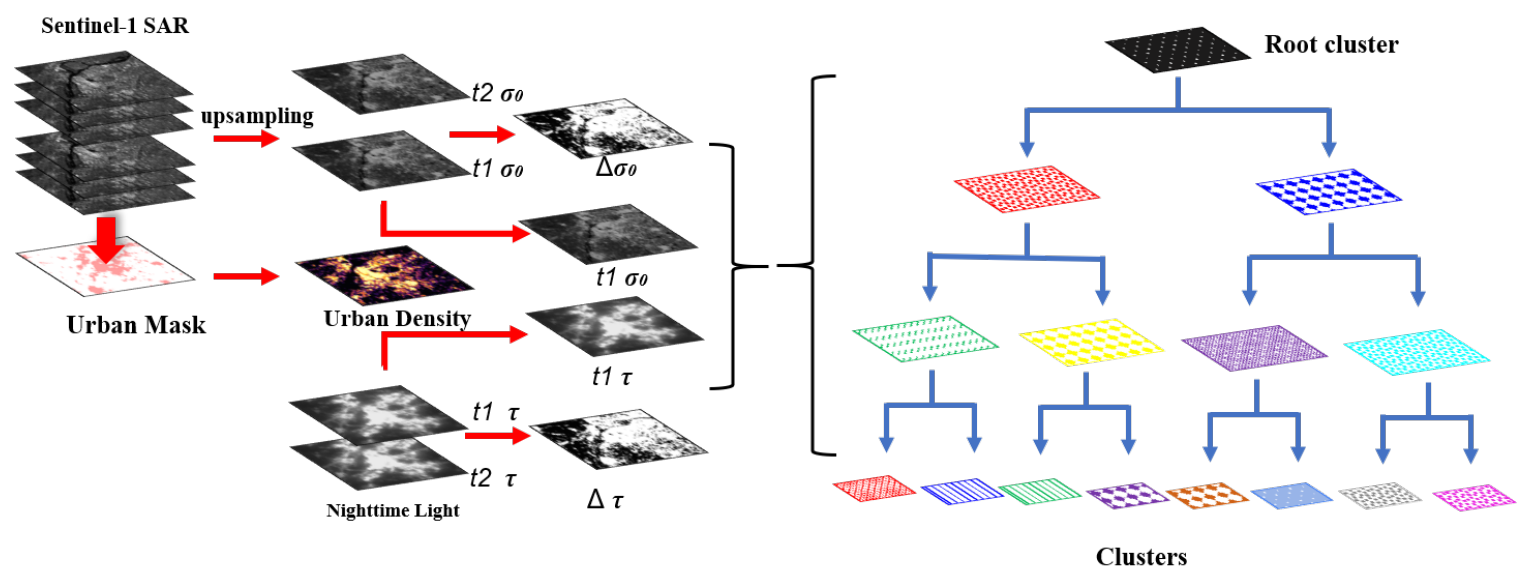

Figure 1. Workflow of the urban change pattern exploration procedure used in this chapter.

Table 1. Interpretation of change patterns in the Yangtze River Delta

\begin{tabular}{|c|c|c|c|c|}
\hline Cluster & Initial state & Change description & Spatial description & Interpretation \\
\hline Blue & $\begin{array}{l}\text { Large values of } \mathrm{NL} \\
\tau \text {, small backscattering } \\
\text { coefficient } \sigma_{0}\end{array}$ & $\begin{array}{l}10-20 \% \text { increase in } \mathrm{VV} \\
\sigma_{0} \text { Almost no change in } \\
\mathrm{NL} \tau \text { and } \mathrm{VH} \sigma_{0}\end{array}$ & $\begin{array}{lrr}\text { Far } & \text { away } & \text { from } \\
\text { urban } & \text { area/river } \\
\text { side/container } & \text { ter- } \\
\text { minal } & & \\
& & \end{array}$ & $\begin{array}{l}\text { Near complete con- } \\
\text { struction of building } \\
\text { blocks }\end{array}$ \\
\hline Black & $\begin{array}{l}\text { Intermediate values of } \\
\tau \text { and } \sigma_{0}\end{array}$ & $\begin{array}{l}\text { About } 10-20 \% \text { increase } \\
\text { in } \mathrm{VV} \sigma_{0} \text { and } \mathrm{VH} \sigma_{0} \text {, } \\
\text { and } 5-10 \% \text { increase in } \\
\tau\end{array}$ & $\begin{array}{l}\text { Sea side Seaside vil- } \\
\text { las/ container terminal/ } \\
\text { urban-rural fringe area }\end{array}$ & $\begin{array}{l}\text { Construction of multi- } \\
\text { storey and medium } \\
\text { height houses }\end{array}$ \\
\hline Orange & $\begin{array}{l}\text { Intermediate or large } \\
\text { values of } \tau \text {, intermedi- } \\
\text { ate or large } \sigma_{0}\end{array}$ & $\begin{array}{l}\text { About } 1-5 \% \text { increase } \\
\text { in } \tau \text {, and almost no } \\
\text { change in } \mathrm{VV} \sigma_{0} \text { and } \\
\mathrm{VH} \sigma_{0}\end{array}$ & Rural areas & $\begin{array}{l}\text { Relatively high density } \\
\text { of low-rise residential } \\
\text { building blocks }\end{array}$ \\
\hline Yellow & $\begin{array}{l}\text { Intermediate values of } \\
\tau \text { and intermediate } \sigma_{0}\end{array}$ & $\begin{array}{l}\text { About } 1-5 \% \text { increase } \\
\text { in } \tau \text {, and almost no } \\
\text { change in } \mathrm{VV} \sigma_{0} \text { and } \\
\mathrm{VH} \sigma_{0}\end{array}$ & Rural areas & $\begin{array}{l}\text { Relatively low density } \\
\text { of low-rise residential } \\
\text { building blocks }\end{array}$ \\
\hline
\end{tabular}

Table 2. Interpretation of change patterns in the Jingjinji megalopolis

\begin{tabular}{|c|c|c|c|c|}
\hline Cluster & Initial state & Change description & Spatial description & Interpretation \\
\hline Blue & $\begin{array}{l}\text { Intermediate values of } \\
\text { NL } \tau \text {, small backscat- } \\
\text { tering coefficient } \sigma_{0}\end{array}$ & $\begin{array}{l}\text { About } 10-15 \% \text { increase } \\
\text { in } \mathrm{VV} \sigma_{0} \text { and } \mathrm{VH} \sigma_{0} \text {, } \\
\text { and } 1-5 \% \text { decrease in } \tau \\
\text { and } \mathrm{VH} \sigma_{0}\end{array}$ & $\begin{array}{l}\text { Urban-rural fringe } \\
\text { areas or areas away } \\
\text { from urban core }\end{array}$ & $\begin{array}{l}\text { Change from low-rise } \\
\text { to high rise/residential } \\
\text { extensions }\end{array}$ \\
\hline Black & $\begin{array}{l}\text { Intermediate or large } \\
\text { values of } \tau \text {, minterme- } \\
\text { diate or large } \sigma_{0}\end{array}$ & $\begin{array}{l}\text { About } 10-20 \% \text { increase } \\
\text { in } \mathrm{VV} \sigma_{0} \text { and more in } \\
\mathrm{VH} \sigma_{0} \text {, and } 1-5 \% \text { in- } \\
\text { crease in } \tau\end{array}$ & $\begin{array}{l}\text { Areas on the seaside } \\
\text { and away from urban } \\
\text { areas }\end{array}$ & $\begin{array}{l}\text { New constructions, } \\
\text { such as factories and } \\
\text { the new Beijing Daxing } \\
\text { international airport }\end{array}$ \\
\hline Orange & $\begin{array}{l}\text { Intermediate values of } \\
\tau \text { and } \sigma_{0}\end{array}$ & $\begin{array}{l}\text { About } 1-5 \% \text { decrease in } \\
\mathrm{VV} \sigma_{0} \text { and increase in } \\
\mathrm{VH} \sigma_{0} \text {, and } 10 \% \text { in- } \\
\text { crease in } \tau\end{array}$ & $\begin{array}{l}\text { Rural residential areas } \\
\text { in the countryside }\end{array}$ & $\begin{array}{l}\text { Towns without obvious } \\
\text { construction activities }\end{array}$ \\
\hline Yellow & $\begin{array}{l}\text { Intermediate or small } \\
\text { values in } \tau \text {, intermedi- } \\
\text { ate } \sigma_{0}\end{array}$ & $\begin{array}{l}\text { About } 5-10 \% \text { decrease } \\
\text { in } \mathrm{VV} \sigma_{0} \text { and more in } \\
\mathrm{VH} \sigma_{0} \text {, and almost no } \\
\text { change in } \tau\end{array}$ & $\begin{array}{l}\text { Areas away from urban } \\
\text { cores }\end{array}$ & $\begin{array}{l}\text { Construction of airfield } \\
\text { runways/new towns }\end{array}$ \\
\hline
\end{tabular}




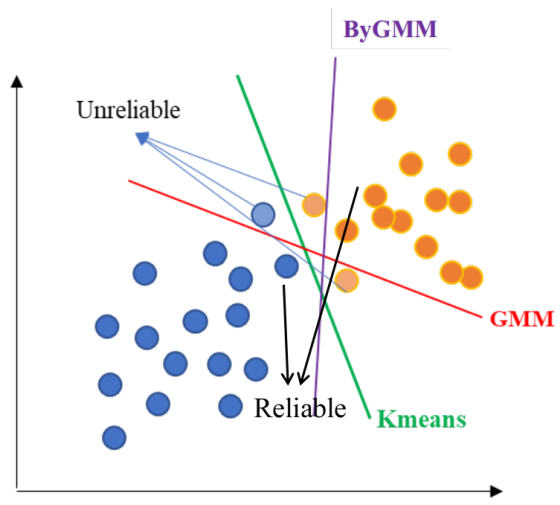

Figure 2. Graphical representation of unreliable and reliable labels.

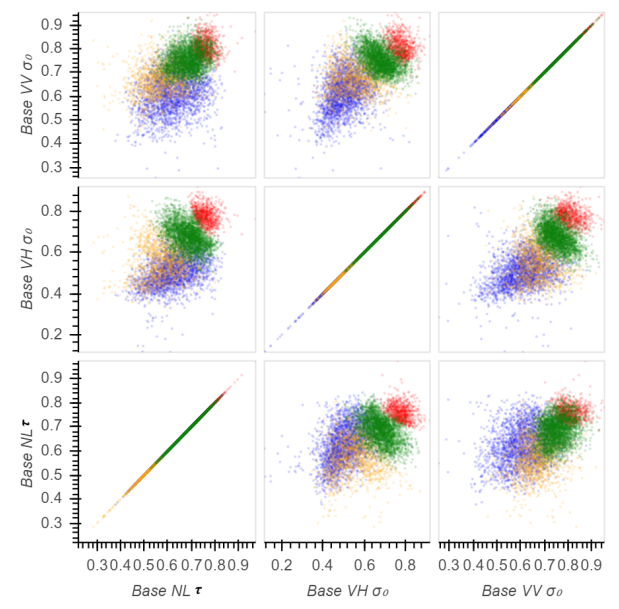

(a)

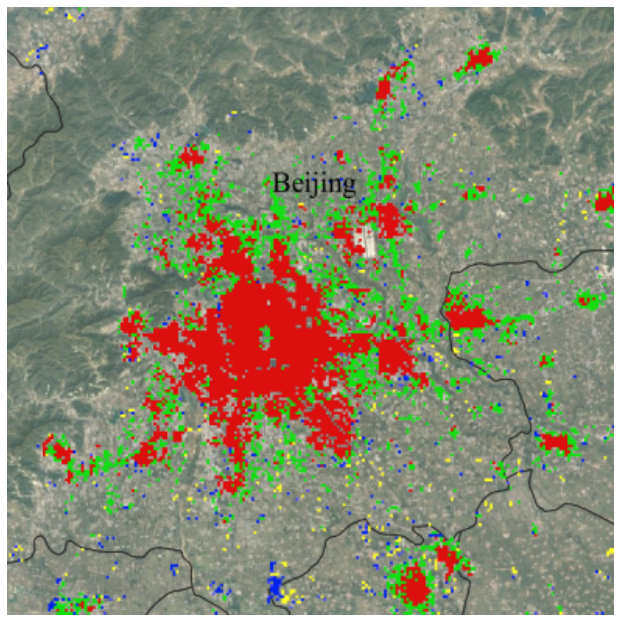

(b)

Figure 3. (a) Bi-dimensional scatterplots of the clusters extracted in the second layer of the hierarchical clustering procedure;

(b)change pattern mapping of the 4-component clusters.

Table 3. Validation of urban extents and recognized clusters.

\begin{tabular}{lcccc}
\hline \hline & \multicolumn{2}{c}{ Urban extents } & \multicolumn{2}{c}{ Change detection } \\
Megalopolis & OA(/100\%) & Kappa & Cluster & Detected Rate (/100\%) \\
\hline \hline YTZ & 98.61 & 0.9289 & $3 / 4$ & 86.67 \\
\hline J J J & 96.51 & 0.8645 & $1 / 2 / 4$ & 83.33 \\
\hline
\end{tabular}

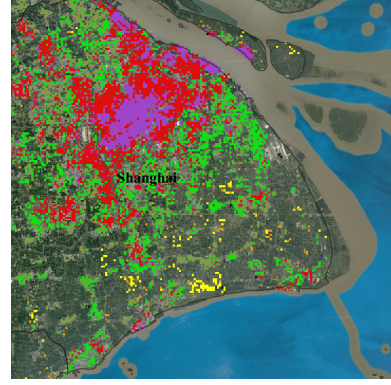

(a)

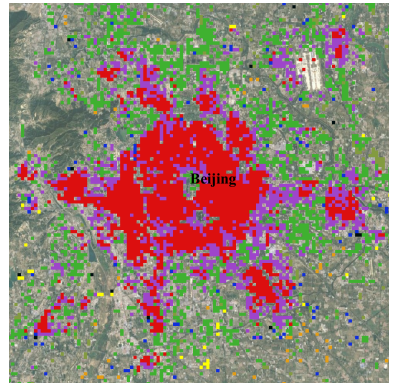

(c)

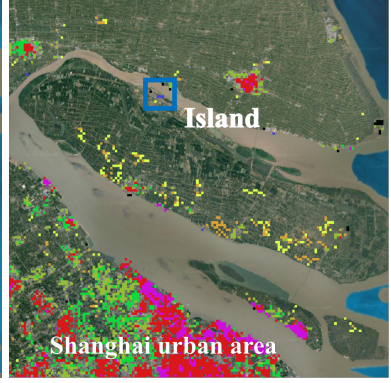

(b)

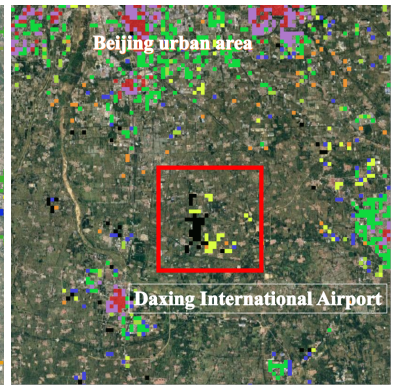

(d)
Figure 4. Spatial location of changes inside and outside urban areas: (a) the 8-component clustering map of the main urban area of Shanghai; (b) small settlements in the island in Yangtze

River Delta; (c) the main urban area of Beijing; (d) small settlements far from it (the black patch inside the red rectangle is the construction site of the new Beijing Daxing International

Airport).

patterns, allowing to recognize both construction/demolition of built-up structures and changes in the economic activity, represented as a proxy by the nighttime lights. Taking into account the initial states of sites under analysis with respect to both backscattering coefficients in SAR images and intensity in nighttime data, detected patterns are clearly differentiated between core and suburban areas, as well as the areas beyond urban outskirts. Specifically, very new development city zones can be singled out and clearly recognized.

\section{REFERENCES}

Blei, D. M., Kucukelbir, A., McAuliffe, J. D., 2017. Variational inference: A review for statisticians. Journal of the American Statistical Association, 112(518), 859-877.

Borghys, D., Shimoni, M., Perneel, C., 2007. Change detection in urban scenes by fusion of sar and hyperspectral data. Remote Sensing for Environmental Monitoring, GIS Applications, and Geology VII, 6749, International Society for Optics and Photonics, 67490R.

Che, M., Gamba, P., 2019. Intra-urban change analysis using Sentinel-1 and Nighttime Light Data. IEEE Journal of Selected Topics in Applied Earth Observations and Remote Sensing, 12(4), 1134-1142.

Corbane, C., Pesaresi, M., Politis, P., Syrris, V., Florczyk, A. J., Soille, P., Maffenini, L., Burger, A., Vasilev, V., Rodriguez, D. et al., 2017. Big earth data analytics on Sentinel-1 and Landsat imagery in support to global human settlements mapping. Big Earth Data, 1(1-2), 118-144. 


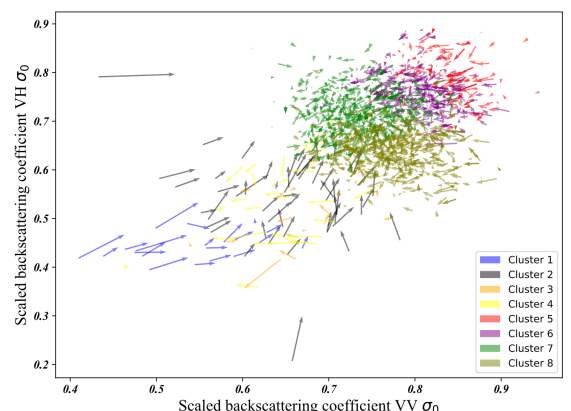

(a)

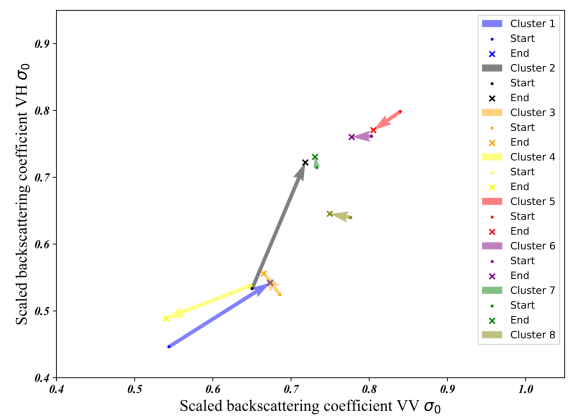

(d)

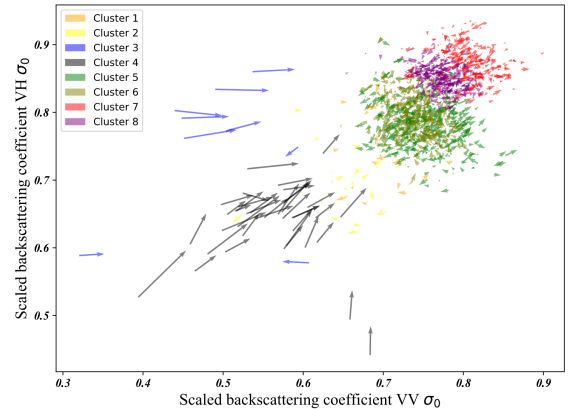

$(\mathrm{g})$

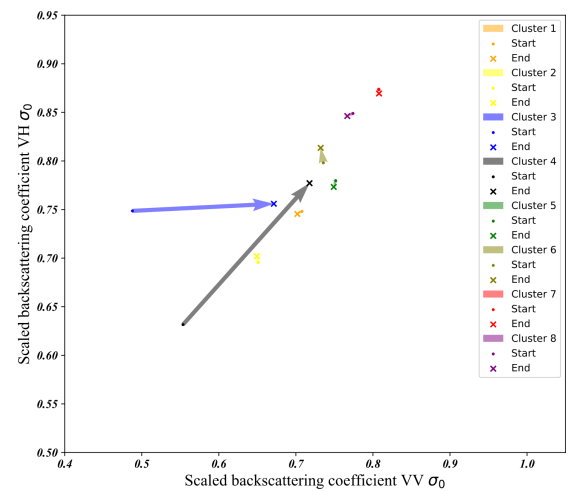

(j)

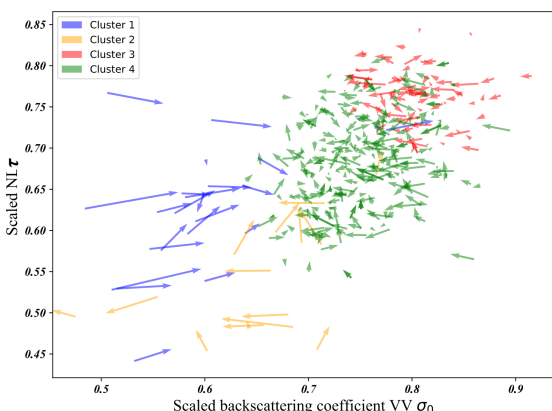

(b)

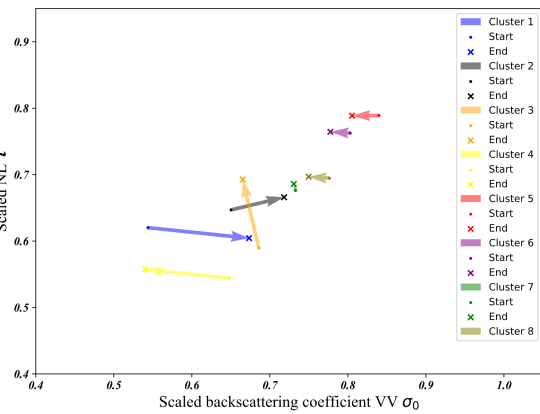

(e)

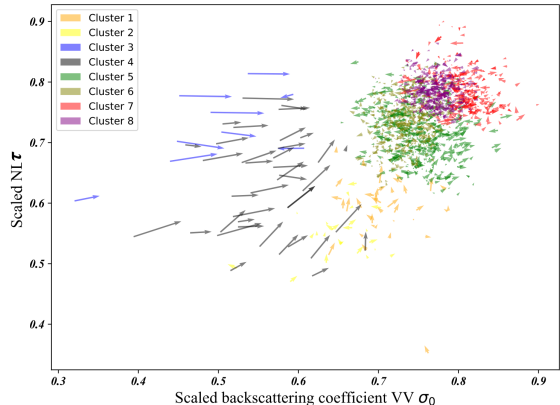

(h)

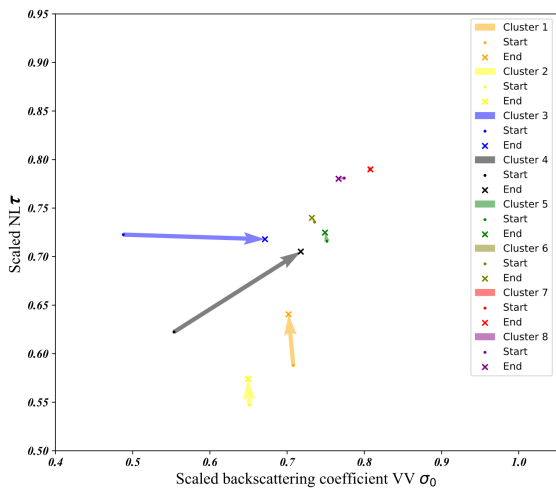

(k)

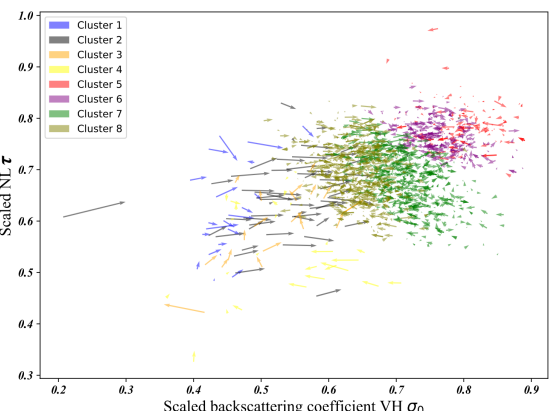

(c)

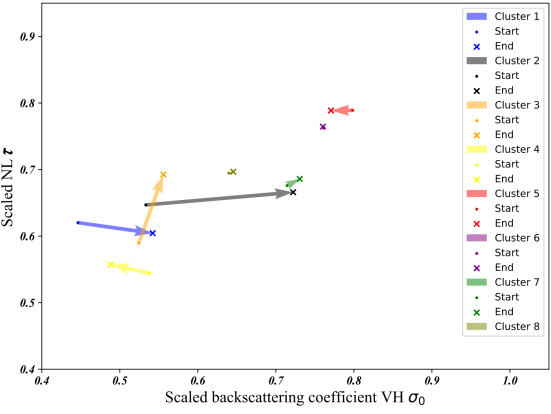

(f)

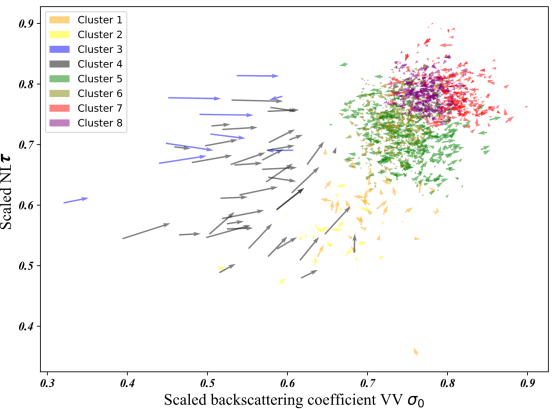

(i)

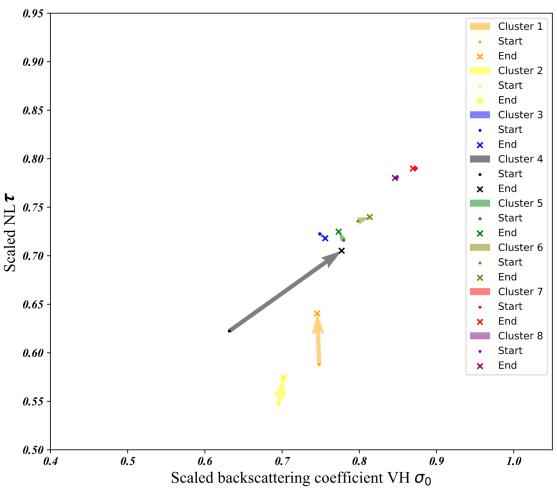

(1)

Figure 5. Vector analysis for the 8 component clusters in the Jingjinji (a-f) and Yangtze River Delta (g-l) megalopolis: (a-c and g-i) using a subset of points; (d-f and j-l) using only the cluster centers. 


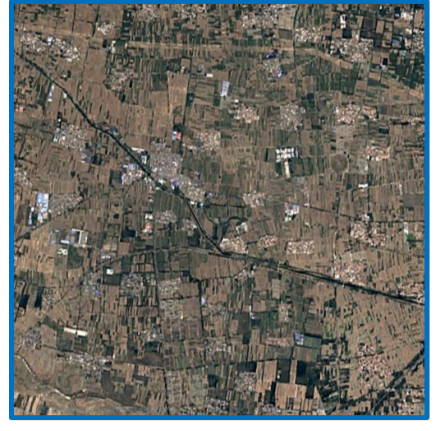

2015.12

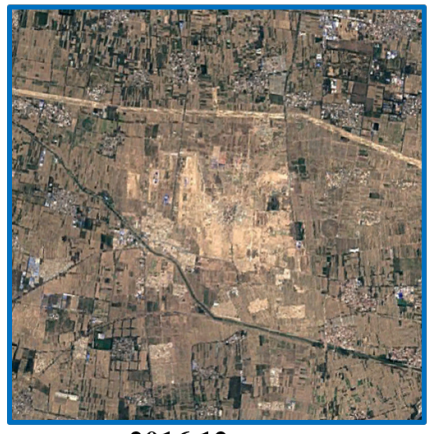

2016.12

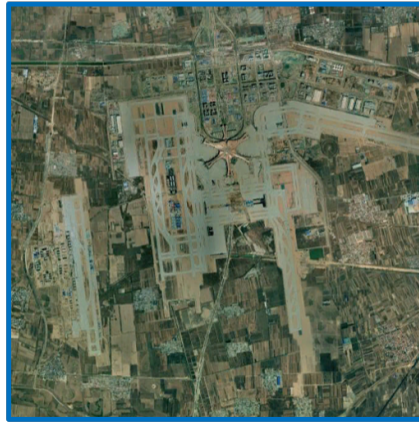

2019.03

(a)

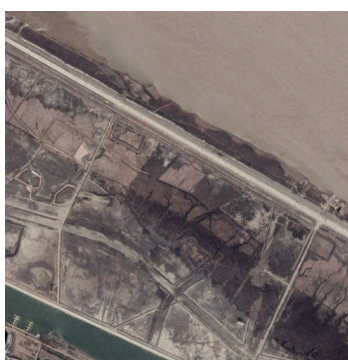

2014-04-06

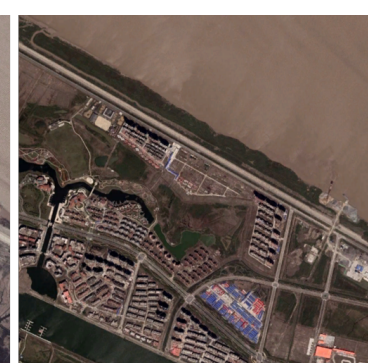

2016-04-18

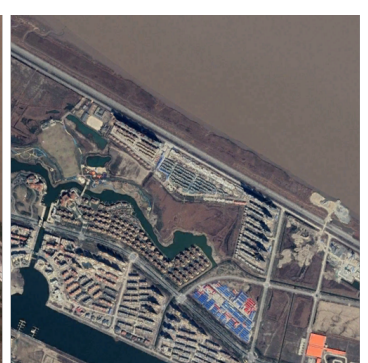

2017-02-12

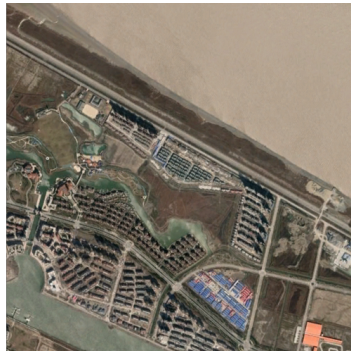

2017-03-03

(b)

Figure 6. Validating change patterns using Google Earth historical images:(a) Beijing Daxing International Airport - see Fig. 4(d); (b) the island in the Yangtze River Delta - see Fig. 4(b).

Frolking, S., Milliman, T., Seto, K. C., Friedl, M. A., 2013. A global fingerprint of macro-scale changes in urban structure from 1999 to 2009. Environmental Research Letters, 8(2), 024004.

Gamba, P., Herold, M., 2009. Global mapping of human settlement: experiences, datasets, and prospects. CRC Press.

Huang, X., Schneider, A., Friedl, M. A., 2016. Mapping subpixel urban expansion in China using MODIS and DMSP/OLS nighttime lights. Remote Sensing of Environment, 175, 92-108.

Lo, C., Choi, J., 2004. A hybrid approach to urban land use/cover mapping using Landsat 7 Enhanced Thematic Mapper Plus (ETM+) images. International Journal of Remote Sensing, 25(14), 2687-2700.

Padmanaban, R., Bhowmik, A. K., Cabral, P., 2019. Satellite image fusion to detect changing surface permeability and emerging urban heat islands in a fast-growing city. PloS one, 14(1), e0208949.

Pernkopf, F., Bouchaffra, D., 2005. Genetic-based EM algorithm for learning Gaussian mixture models. IEEE Transactions on Pattern Analysis and Machine Intelligence, 27(8), 1344-1348.

Rutkowski, J., Canty, M. J., Nielsen, A. A., 2018. Site Monitoring with Sentinel-1 Dual Polarization SAR Imagery Using Google Earth Engine. Journal of Nuclear Materials Management, 46(3), 48-59.

Salentinig, A., Gamba, P., 2016. Multiscale multisensor decision level data fusion for urban mapping. 2016 4th International Workshop on Earth Observation and Remote Sensing Applications (EORSA), IEEE, 67-71.
Taofang, Y., 2005. Boundary Analysis of the Jing-Jin-Ji Global City-Region. Geography and Geo-Information Science, 4.

Taubenböck, H., Esch, T., Felbier, A., Wiesner, M., Roth, A., Dech, S., 2012. Monitoring urbanization in mega cities from space. Remote sensing of Environment, 117, 162-176.

Tuong, V. T., Thy, P. T. M., Lam, N. D., 2018. Multiscale remote sensing of urbanization in Ho Chi Minh city, Vietnam-A focused study of the south.

Wang, B., Zheng, J., 2006. Research on the evaluation of land intensive utilization in megalopolis of China. J. Univ. Sci. Technol. Beijing (Soc. Sci. Ed.), 22, 24-28.

Wang, S., Xing, J., Zhao, B., Jang, C., Hao, J., 2014. Effectiveness of national air pollution control policies on the air quality in metropolitan areas of China. Journal of Environmental Sciences, 26(1), 13-22.

Wu, Y., Li, S., Yu, S., 2016. Monitoring urban expansion and its effects on land use and land cover changes in Guangzhou city, China. Environmental monitoring and assessment, 188(1), 54.

Yu, T., Wu, Z., 2005. Boundary analysis of the Yangtze delta megalopolis region. Resources and Environment in the Yangtze Basin, 14(4), 398-403.

Revised Jan. 2020 